\title{
Revisión de tema
}

\section{Prolactina en pacientes con trastornos endocrinos y de fertilidad}

\author{
Dres.: Ariel Iván Ruiz *; Catalina Acevedo **; \\ William Onatra H. $* * *$
}

\section{REVISION DEL CONOCIMIENTO}

\section{INTRODUCCION}

La prolactina (PRL) es una hormona polipeptídica secreta por los lactotropos de la hipófisis. Está constituida por 198 aminoácidos con una leucina $\mathrm{NH}_{2}$ terminal, tres puentes disulfuro y un peso molecular de 22.500 daltons (1). El término prolactina fue ideado por Riddle en 1933; en 1970 Frantz y Kleinberg desarrollaron un bioanálisis in vitro y en 1971 Hwang y colaboradores desarrollaron un método de RIA para la prolactina. La estructura de la prolactina fue descrita por Shone y Parlow en 1977 (1).

La hormona circula en formas heterogéneas: PRL monomérica ("Little PRL") (PM 22.500 daltons); gran PRL, (PM 50.000 daltons); gran-gran PRL ("big-bigPRL con PM mayor de 100.000 daltons) (2); y la forma glicosilada de la PRL con un PM de 25.000 daltons. Estas formas heterogéneas de la PRL se han encontrado en estados normales e hiperprolactinémicos. La heterogeneidad de la PRL circulante puede ser la responsable de la discrepancia que existe en pacientes con niveles altos de PRL por RIA, con ciclos menstruales normales y sin galactorrea (3). La PRL monomérica ("little PRL) tiene afinidad por el receptor y bioactividad alta y las formas de gran-gran-PRL tienen aparentemente bajas propiedades de unión al receptor $(3,4)$.

Instructor Asistente.

R3 de Ginecología y Obstetricia.

*** Profesor Asistente. Departamento de Obstetricia y Ginecología. Universidad Nacional de Colombia. Instituto Materno Infantil Bogotá.
La prolactina guarda alta homología estructural con la hormona del crecimiento y la hormona lactógeno placentaria y se cree que el gen de la prolactina localizado en el cromosoma del humano se derivó de un gen precursor común somatomamotrófico (hGH-hPRLhPL) hace unos 300 millones de años (3).

La prolactina actúa en un receptor de la membrana celular aparentemente sin mediación del AMPc.

\section{FISIOLOGIA DE LA PROLACTINA}

La hormona tiene un patrón de secreción pulsátil (cada 8 a 10 minutos), un ritmo circadiano: su nivel aumenta con el sueño alcanzando el máximo entre las 3 y las 5 AM y disminuyendo a la hora de levantarse. Se han descrito numerosas funciones de la PRL; aquí se describen aquellas que tienen importancia en reproducción:

\section{A. Glándula Mamaria y Lactancia}

La prolactina es necesaria en la acción de estrógenos y progesterona, para estimular el desarrollo del seno durante el embarazo para iniciar y mantener la lactancia. Insulina, hidrocortisona y PRL inducen la producción de RNAm específico para la síntesis de caseína; la PRL también aumenta la síntesis y secreción de lactoalbúmina, grasas lácteas y lactosa (5).

A la décima semana de gestación aumenta los niveles de PRL, alcanzando 100 a $200 \mathrm{ng} / \mathrm{ml}$ al término del embarazo; estos niveles elevados y la desaparición postparto de inhibición por los estrógenos y progesterona, inician la lactancia. En las mujeres que lactan la prolactina aumenta con la succión pero, al transcurrir 
el tiempo, este aumento disminuye y desaparece entre el cuarto y sexto mes postparto (6).

El estímulo de la succión es un reflejo neuroendocrino que se inicia en receptores sensoriales del pezón, los impulsos ascienden a través de la médula espinal y alcanzan el hipotálamo, la succión estimula además la secreción de oxitocina por la hipófisis posterior.

Recientemente se ha propuesto un modelo para la regulación de la secreción de PRL durante la lactancia, según el cual la liberación de PRL es controlada por dos vías interdependientes (7): una involucra las neuronas tuberohipofisiarias (TH) del sistema dopaminérgico, la dopamina (DA), la hipófisis posterior, el factor liberador de dopamina (PRH) y los vasos porta cortos $\mathrm{y}$, la otra, involucra las neuronas tuberoinfundibulares del sistema dopaminérgico (TIDA), la DA, el PRH y los vasos porta largos. El estímulo de la succión, mediado por la serotonina, afecta la vía TH del sistema dopaminérgico; éste suprime la DA y estimula la secreción del PRH por la hipófisis posterior el cual alcanzaría la hipófisis anterior a través de los vasos porta cortos. La segunda vía involucra una inhibición por retroalimentación de asa corta por PRL y otros moduladores sobre la vía TIDA. El modelo asume que la liberación del PRL y oxitocina por la succión se controlan en la hipófisis posterior. La verificación de este modelo debe incluir la demostración del PRH en la hipófisis posterior (7) (Fig. 1).

En la leche, la liberación de PRL en las secreciones intraalveolares juega algún papel en el establecimiento y mantenimiento de la lactancia. La PRL en la leche es biológicamente activa y es absorbida por el recién nacido. La transmisión temprana de la PRL en la leche acuosa del inicio de la succión, tiene un efecto obligatorio sobre el intercambio intestinal de líquidos y electrolitos en el recién nacido humano; en el intestino, la PRL influye sobre el transporte de líquidos, sodio, potasio y calcio (8).

\section{B. Líquido Amniótico}

En el líquido amniótico la PRL está en las concentraciones más altas en los dos primeros trimestres del embarazo, disminuyendo desde la semana 25 hasta el término. Esta PRL es producida por la decidua y atraviesa las membranas fetales. En el líquido amniótico tendría una función osmorreguladora efectuando movimiento del agua a través de las membranas (9). Experimentalmente se ha encontrado que aumenta la síntesis del agente tensoactivo.

\section{FIGURA 1 \\ MODELO DE LA REGULACION DE \\ LA SECRECION DE PRL DURANTE LA LACTANCIA. TOMADO DE BEN-JONATHAN $N$.}

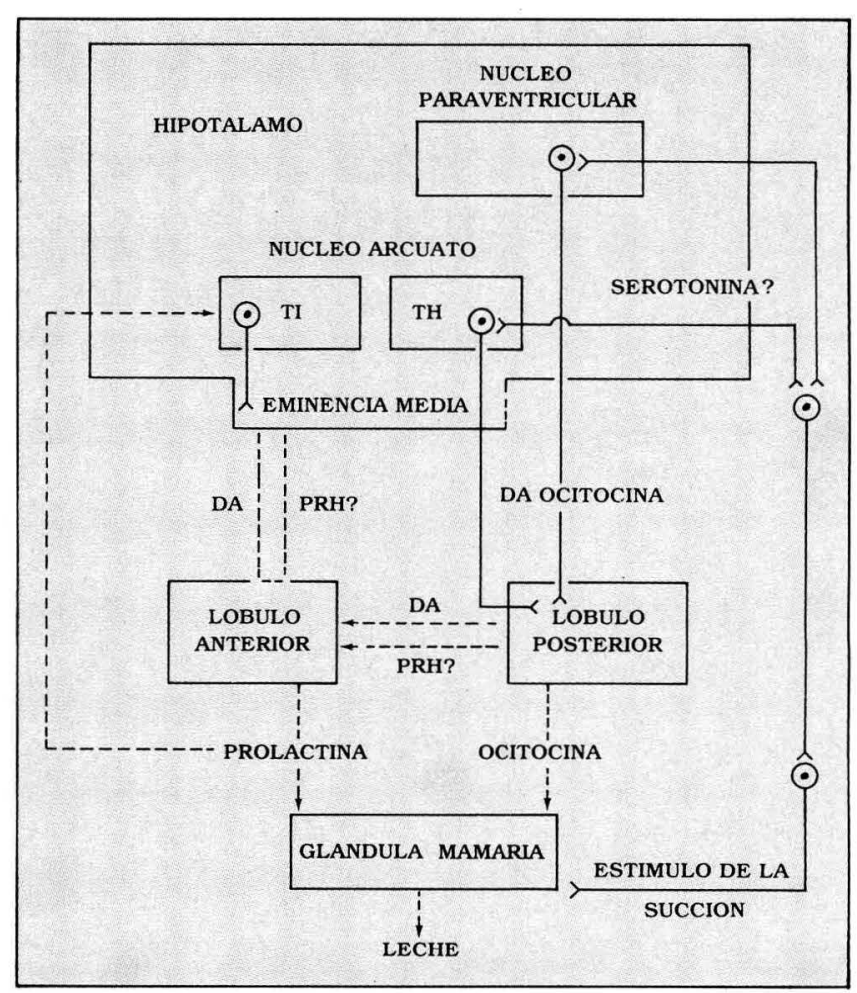

\section{Líquido Folicular}

Los niveles de PRL son altos en el líquido folicular en la fase folicular temprana, disminuyen a niveles bajos preovulatorios y se elevan nuevamente en la fase medioluteal. En concentraciones fisiológicas la PRL facilita la producción de progesterona por el cuerpo lúteo pero, en concentraciones superiores a $20 \mathrm{ng} / \mathrm{ml}$ inhiben la síntesis de progesterona. La modulación de estos efectos parece depender de los estrógenos: en el folículo temprano la PRL inhibe la producción de progesterona, mientras que en las células granulosas la acción del estrógeno y PRL facilitan la producción de progesterona.

\section{Endometrio}

El endometrio decidualizado sintetiza y libera PRL durante la semana anterior a la menstruación. El aumento de prolactina comienza después del día 22 del ciclo y se continúa en las etapas tempranas del embarazo por lo que se le ha implicado en el proceso de implantación (10). 


\section{REGULACION DE LA SINTESIS Y SECRECION DE PROLACTINA}

\section{A. Sustancias inhibidoras}

1. Dopamina (DA). La DA ejerce el control inhibitorio primario de la producción de PRL. La DA se forma por la hidroxilación de fenilalanina a dihidroxifenilalanina la cual es decarboxilada para formar DA (11) (Fig. 2). Dos sistemas dopaminérgicos participan en la regulación de la secreción de PRL: el tuberoinfundibular (TIDA) y el tuberohipofisiario (TH). El TIDA se extiende desde los núcleos arcuato y periventricular del hipotálamo basal hasta la eminencia media y el tallo hipofisiario; desde este sitio la DA alcanza el lóbulo anterior de la hipófisis a través de los vasos porta largos. El TH tiene terminales en el lóbulo posterior de la hipófisis. La DA del lóbulo posterior a través de los vasos porta cortos, alcanza el lóbulo anterior y ejerce también regulación de la PRL. La activación de uno u otro sistema depende de la naturaleza de los estímulos hormonales o neuronales (Fig. 1).

Se han caracterizado por lo menos dos tipos de receptores para DA: los denominados D2 (Receptor D2DA) localizados en los lóbulos intermedio y anterior de la hipófisis, disminuyen o no tienen ningún efecto sobre la formación del AMPc. Se propone que un agonista (A) se une al receptor (R) para formar un complejo agonista-receptor (A-R). Esto induce un cambio conformacional en el receptor que lo capacita para acoplarse a una proteína reguladora inhibitoria (NI) ligada al nucleótido de guanina. El complejo A-R-NI sirve como unión para inhibir la subunidad catalítica de la adenilciclasa.

En resumen, la inhibición de la secreción de prolactina, por la dopamina se asocia con un acoplamiento funcional entre el receptor y la proteína NI (7). La secreción de prolactina es dependiente de calcio; la dopamina disminuye el influjo de calcio en el lactotropo e inhibe la hidrólisis de fosfatidilinositolbifosfato que tiene relación con la movilización del calcio. De esta forma disminuye el calcio disponible para la exocitosis de la prolactina.
2. Otras sustancias inhibidoras. El GABA

ejerce un control inhibitorio en la hipófisis anterior a través de receptores específicos, pero estimulatorio a nivel central a través de la inhibición del TIDA. La prolactina regula su propia liberación por un mecanismo de retroalimentación de asa corta que involucra al TIDA.

\section{B. Sustancias estimulatorias}

1. Hormona liberadora de tirotropina

(TRH). Es un potente estimulador de la secreción de prolactina que actúa a nivel de los lactotropos (11).

2. Opioides. Los opioides y sus agonistas elevan la prolactina. Los opioides endógenos pueden participar en la liberación de la prolactina por stress; ellos disminuyen la síntesis de dopamina en la eminencia media.

3. Serotonina. Se asocia con la elevación que ocurre durante la succión (12), el sueño y el estrés. La succión desencadena reflejos que activan vías serotoninérgicas ascendentes que alcanzan el hipotálamo.

4. Péptido Intestinal Vasoactivo (VIP). El péptido intestinal vasoactivo estimula la secreción de prolactina actuando directamente a nivel de la hipófisis anterior (7).

5. Hormonas Esteroideas. Los estrógenos

estimulan la síntesis, almacenamiento y secreción de prolactina, antagonizan la actividad de la dopamina, aumentan la secreción de prolactina inducida por TRH y aumentan el número de lactotropos; la marcada elevación de la prolactina al final del embarazo depende de los estrógenos (13). La testosterona exógena por aromatización a estradiol puede aumentar la producción de prolactina y el crecimiento de los lactotropos (14).

6. Receptores de $\mathbf{H}_{1}$ y $\mathbf{H}_{2}$. Relacionados con el control de la secreción de prolactina durante la lactancia y sueño. Los antagonistas $\mathrm{H}_{1}$ inhiben la secreción mientras que los bloqueadores $\mathrm{H}_{2}$ la aumentan.

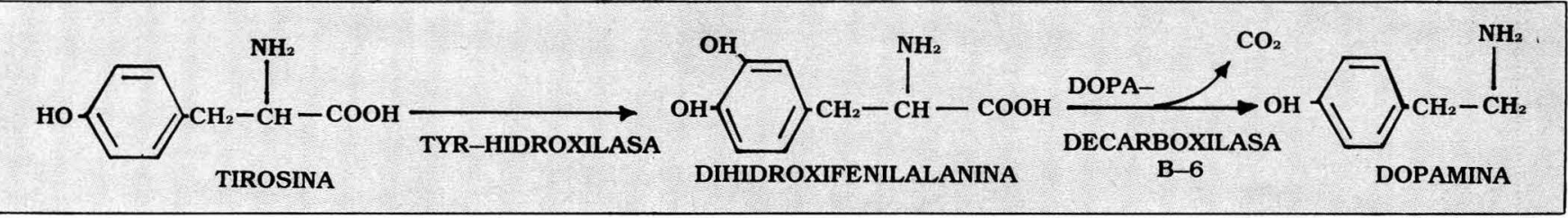




\section{Otras sustancias que regulan la prolactina}

Otros neurotransmisores se relacionan con la modulación de la prolactina pero su significado biológico está aún bien establecido: Bombesina, Sustancia P, CCK, neurotensina, etc.

\section{HIPERPROLACTINEMIA}

A. Etiología $(3,11,15,16,17,18,19)$

1. Causas Fisiológicas
a. Embarazo
b. Ejercicio
c. Estrés (incluyendo cirugía)
d. Relación Sexual
e. Sueño
f. Lactancia, succión y estimulación del pezón

2. Causas Farmacológicas
a. Drogas Psicotrópicas
1. Fenotiazinas
2. Butirofenonas
3. Antidepresivos
4. Sulpiride
5. Anfetaminas, alucinógenos
b. Drogas Antihipertensivas
1. Reserpina
2. Alfametildopa
c. Contraceptivos orales-estrógenos
d. Agentes Anestésicos
e. Otras (Metoclopramida, cimetidina)

\section{Hipotalámicas}
a. Funcionales
b. Orgánicas
1. Sarcoidosis
2. Histiocitosis $X$
3. TBC
4. Neoplasias (incluyendo metastásicas)

\section{Hipofisiarias}
a. Prolactinomas
b. Adenomas no lactotrópicos
c. Otros tumores hipofisiarios

5. Tumores no hipofisiarios (craneofaringioma)

6. Sección del tallo hipofisiario

\section{Otras}
a. Hipotiroidismo primario
b. Síndrome de Nelson
c. Acromegalia
d. Síndrome de Cushing
e. Insuficiencia renal
f. Cicatrices torácicas
g. Producción ectópicas por tumores (hiperne- froma CA Broncogénico)
h. Pseudociesis

\section{B. Fisiopatología}

1. Causas fisiológicas. Fueron discutidas en

las secciones precedentes, así como, los efectos de los estrógenos.

2. Causas Farmacológicas. Las butirofenonas y sustancias relacionadas (espirofenona, haloperidol, domperidona) y la metoclopramida, se unen selectivamente a los receptores D2DA y antagonizan la DA endógena aumentando así la secreción de prolactina. El nivel de prolactina en estos casos rara vez es superior a $80 \mathrm{ng} / \mathrm{ml}$. Reserpina y alfa metildopa agotan la dopamina hipotalámica. Anfetaminas y alucinógenos estimulan el sistema serotoninérgico (3).

3. Enfermedades Hipotalámicas. Los procesos que interfieren la circulación portal o afectan los centros de producción de DA pueden producir hiperprolactinemia.

4. Enfermedades Hipofisiarias. El tumor hipofisiario más común es el adenoma productor de PRL que constituye cerca del $25 \%$ de los adenomas hipofisiarios. Se conforma de células ovales con RER bien desarrollado y gránulos electrodensos de $600 \mathrm{~nm}$ de diámetro; muchos tienen escasa granulación y no toman tinción acidófila razón por la cual se les conocía como cromófobos (18). Se ha determinado la existencia de una célula progenitora de somatotropos y lactotropos que podría ser el origen de los tumores hipofisiarios secretantes de PRL y hormona de crecimiento (20).

Adenomas hipofisiarios no productores de PRL o aún enfermedades no adenomatosas en la región hipofisiaria, pueden interferir físicamente con el sistema porta desconectando las células lactotropas de la hipófisis anterior del control inhibitorio dopaminérgico hipotalámico, llevando a hiperprolactinemia (21).

El craneofaringioma es un tumor no hipofisiario que puede producir hiperprolactinemia por este mecanismo (11). Así el aumento de volumen selar asociado con hiperprolactinemia no siempre se debe a adenoma hipofisiario secretor de prolactina.

El mecanismo inhibitorio de la DA se encuentra relativamente intacto en la mayoría de los prolactinomas humanos; estos tumores receptores y mecanismo postreceptor conservados y se desconoce la etiología de los mismos, (7) así como, su historia natural (17).

5. Hipotiroidismo primario. En el hipotiroidismo primario se aumenta la TRH que, actuando directamente en los lactotropos, libera PRL. Se ha propuesto un modelo para explicar el aumento de TSH, 
PRL y LH que ocurren en el hipotiroidismo primario, según el cual, la síntesis o secreción disminuida de DA en el hipotálamo llevaría a la pérdida de la inhibición que ejerce la DA sobre TSH, PRL y LH. (Fig. 3) (22).

FIGURA 3

\section{MECANISMO DE AUMENTO DE TSH, PRL Y LH EN EL HIPOTIROIDISMO PRIMARIO MODIFICADO DE THOMAS Y REID}

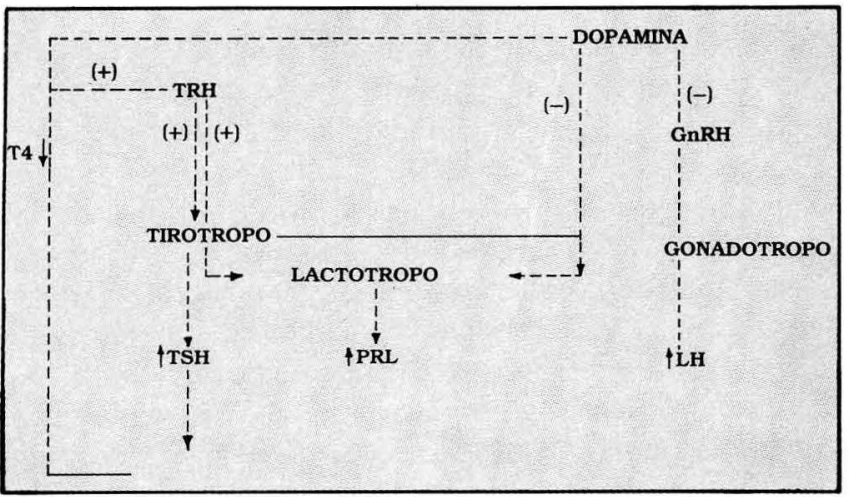

6. Acromegalia. La activación de un receptor

hormonal por otra hormona de estructura similar se conoce como "Specifiaty Spillover" (24). Una hormona tiene afinidad por su receptor, pero puede tener también afinidad por el receptor de una hormona relacionada; a concentraciones físiológicas, la afinidad por el segundo receptor es tan baja que las consecuencias de este "entrecruzamiento" es despreciable. Pero, cuando la hormona tiene una concentración excesiva, se pueden observar sus efectos sobre el receptor de una segunda hormona (esté o no presente la segunda hormona) (25). En algunos pacientes con acromegalia ocurre el síndrome hiperprolactinémico; un subgrupo de tales pacientes tienen elevado el nivel de prolactina, pero una gran fracción de pacientes con acromegalia que tienen el síndrome hiperprolactinémico tienen niveles NORMALES de PRL; el síndrome puede resultar de un efecto de "Spillover" de la hormona de crecimiento sobre el receptor de PRL a estas pacientes (25). En condiciones normales el efecto de Spillover de la hGH sobre el receptor de la PRL, es despreciable pues la concentración de hGH es mucho menor que la de PRL. (Fig 4).

7. Insuficiencia renal. Por depuración metabólica disminuida y aumento de la producción de PRL.

\section{Cuadro clínico de la hiperprolactinemia}

En la edad reproductiva se presenta en la mujer un cuadro progresivo de insuficiencia lútea, oligoovulación, oligomenorrea y amenorrea (26). Puede ocurrir
FIGURA 4

\section{REPRESENTACION ESQUEMATICA DE LA RELACION ENTRE GH, PRL Y SUS RECEPTORES EN ESTADOS DE EXCESO DE HORMONA}

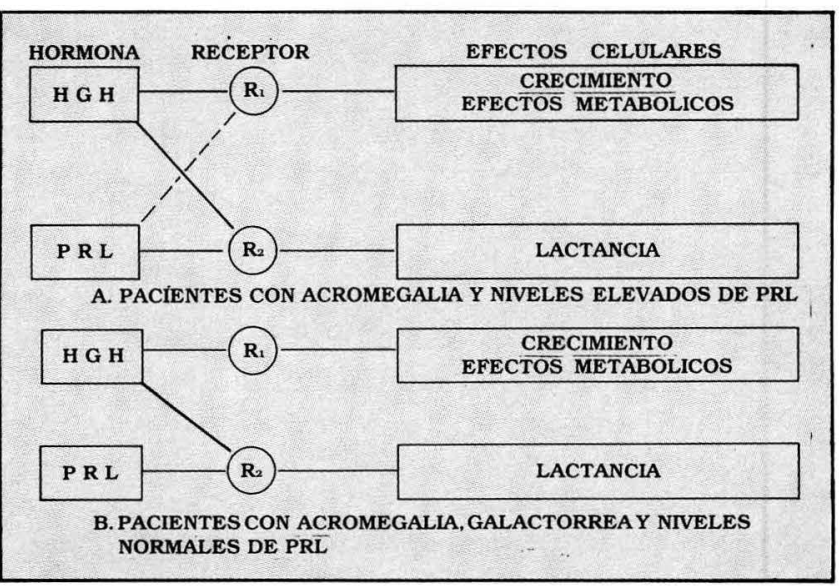

galactorrea pero, muchas pacientes con niveles elevados de PRL no la presentan dependiendo de la bioactividad de la hormona, de otros factores endocrinos y de la sensibilidad individual, (15) por otro lado, aproximadamente la mitad de las pacientes con galactorrea aislada tienen PRL normal. Casi la mitad de las pacientes con amenorrea y galactorrea tienen un microadenoma (tumor menor de $10 \mathrm{~mm}$ ) o un macroadenoma (tumor mayor de $10 \mathrm{~mm}$ ) productor de PRL. Otros hallazgos son: infertilidad, disminución de la líbido y trastornos visuales y/o neurológicos que dependen de las lesiones neoplásicas o su extensión (27).

Las cifras siguientes, tomadas de la revisión de Quigley, (26), enfatizan la importancia de los hallazgos clínicos:

15 a $40 \%$ de pacientes con amenorrea tienen hiperprolactinemia.

79 a $97 \%$ de pacientes con amenorrea y galactorrea tienen hiperprolactinemia.

62 a $95 \%$ de pacientes con tumores hipofisiarios tienen hiperprolactinemia.

36 a $48 \%$ de pacientes con amenorrea e hiperprolactinemia tienen tumores y 28 a $30 \%$ de pacientes con galactorrea no tienen hiperprolactinemia.

Cuando el nivel de PRL es mayor de $100 \mathrm{ng} / \mathrm{ml}$ aproximadamente la mitad de las pacientes tienen un tumor hipofisiario y un nivel superior a $300 \mathrm{ng} / \mathrm{ml}$ prácticamente siempre se asocia con tumor $(15,26)$. Sin embargo, la mayoría de los tumores hipofisiarios tienen niveles de PRL dentro de rango de la hiperprolactinemia de causa farmacológica y hay pacientes con PRL normal y tumor hipofisiario (19). Con la capacidad para medir PRL los epónimos: síndrome de Argonz del Castillo, 
síndrome de Forbes -Albright y síndrome de ChiariFrommel tienen sólo valor histórico (28).

En el hombre se presenta en la edad reproductiva impotencia, disminución de la líbido, infertilidad, galactorrea y trastornos visuales y/o neurológicos.

Si el trastorno es antes de la edad reproductiva puede ocurrir pubertad retardada, signos de hipogonadismo hipogonadotropo en ambos sexos y amenorrea primaria en la mujer (29).

La hiperprolactinemia en niños y adolescentes en muy rara y es frecuentemente producida por causas diferentes a adenomas secretores de PRL. La mayoría de estos pacientes presentan pubertad retardada, pero se han descrito pacientes con pubertad precoz; en niños una estimulación predominante del eje inmaduro por la hiperprolactinemia podría explicar la pubertad precoz (30).

\section{Diagnóstico}

1. Historia Clínica y Examen Físico. Las

causas fisiológicas y farmacológicas deben interrogarse y ser excluidas antes de iniciar una investigación más profunda; de igual forma ocurre con otras enfermedades endocrinas y generales cuyos estigmas clínicos se deben buscar cuidadosamente.

2. Dosificaciones Hormonales. El estudio se inicia con la dosificación de PRL cuyo nivel es hasta $20 \mathrm{ng} / \mathrm{ml}$ (o menos de $500 \mathrm{~m} \mathrm{Ul} / \mathrm{ml}$ ). Se ha aconsejado practicar por lo menos dos determinaciones, cada una con tres muestras ("pool"), sin embargo, cuando los niveles son significativamente altos ésto se hace innecesario.

Se deben dosificar FSH y LH como parte de la investigación de la reserva hipofisiaria y por la inhibición de la GnRH que se presenta en la hiperprolactinemia, probablemente, como resultado de un aumento compensatorio de DA.

El hipotiroidismo primario debe descartarse con la determinación de TSH y T4. Si se encuentran signos de deficiencia o exceso de una o más hormonas trópicas de la hipófisis anterior deben investigarse. Los estudios extensos de la función hipofisiaria sólo se realizan si están clínicamente indicados (31). En estas pacientes puede encontrarse hipoestrogenemia, niveles de progesterona bajos y niveles de DHEA-S y DHEA elevados con androstenediona normal (31).

3. Pruebas Dinámicas. Se han diseñado estudios dinámicos de supresión de la secreción de prolactina (L-dopa, prirdoxina, nomifensina, antagonistas de la serotonina) y de estimulación (TRH, clorpromazina, derivados de la procainamida, hipoglicemia inducida por la insulina, cimetidina), con el fin de diferenciar las causas tumorales de las no tumorales de hiperprolactinemia. Ninguna llena los requisitos de sensibilidad y especificidad para este propósito y no tienen por lo tanto valor discriminativo $(15,17,19,27)$. Probablemente pueden ayudar a valorar la reserva hipofisiaria.

\section{Estudios Radiológicos}

a. Rx Silla Turca: Con este método se pueden detectar lesiones tumorales mayores de $13 \mathrm{~mm}$. Las alteraciones más frecuentemente encontradas son el aumento del volumen de la silla turca, el doble piso selar por depresión asimétrica, erosión del piso de la silla turca, adelgazamiento del dorso de la silla turca, alteraciones en las clionoides y ocasionalmente, densidad de tejidos blandos por extensión esfenoidal (27). Vale la pena recordar que algunas pacientes con hipotiroidismo primario presentan alteraciones radiológicas de la silla turca.

Desventajas: Aproximadamente un $75 \%$ de pacientes con microadenomas demostrados en cirugía tienen silla turca normal y hay variaciones anatómicas normales que no pueden distinguirse de un tumor por esta técnica.

b. Politomografía de la Silla Turca: Puede detectar tumores de $5 \mathrm{~mm}$ de diámetro, anormalidades localizadas de la silla turca y definir las variaciones anatómicas.

Desventajas: Exposición alta a los Rayos X, existe la posibilidad de cambios selares menores en la politomografía en un tercio de mujeres normales.

c. Tomografía Axial Computarizada: Per-

mite la visualización directa de las masas, detecta lesiones hasta de $3 \mathrm{~mm}$, ofrece información sobre el hipotálamo y el tallo hipofisiarios y permite valorar la extensión supraselar (17).

Desventajas: Costos y exposición a los Rayos X.

5. Estudios Oftalmológicos: La extensión supraselar de un tumor produce alteraciones en el campo visual. (Ej. Hemianopsia bitemporal). En la mayoría de pacientes con microprolactinomas no ocurren alteraciones visuales.

\section{E. Tratamiento}

El manejo dependerá de la causa determinante: la supresión de los fármacos psicoactivos conduce a la 
normalización de los niveles de PRL dentro de las 76 horas siguientes a la suspensión de la droga; si los niveles permanecen elevados después de este tiempo deben hacerse investigaciones adicionales (26).

La suplencia de hormona tiroidea en el hipotiroidismo primario normaliza los niveles de prolactina.

El manejo de las lesiones hipofisiarias productoras de PRL incluyen: Observación, Tratamiento Médico, Cirugía y Radioterapia.

a. Observación. Aunque las secuelas neurológicas de los microprolactinomas son inusuales, se presentan las endocrinológicas. La observación debe ser decidida por el médico y la paciente y requiere seguimiento clínico, hormonal y radiológico estrictos. Se contraindica la observación en los macroprolactinomas.

b. Tratamiento Médico. La 2-bromobromoergocriptina es efectiva en el manejo de la hiperprolactinemia de origen funcional y tumoral (tanto en micro como en macroprolactinomas). La bromocriptina se compone de un residuo de ácido lisérgico y una fracción tripeptídica y tienen estructura similar a la DA (Fig. 5) $(17,32)$.

FIGURA 5

\section{ESTRUCTURA DE LA BROMOCRIPTINA Y LA DA}

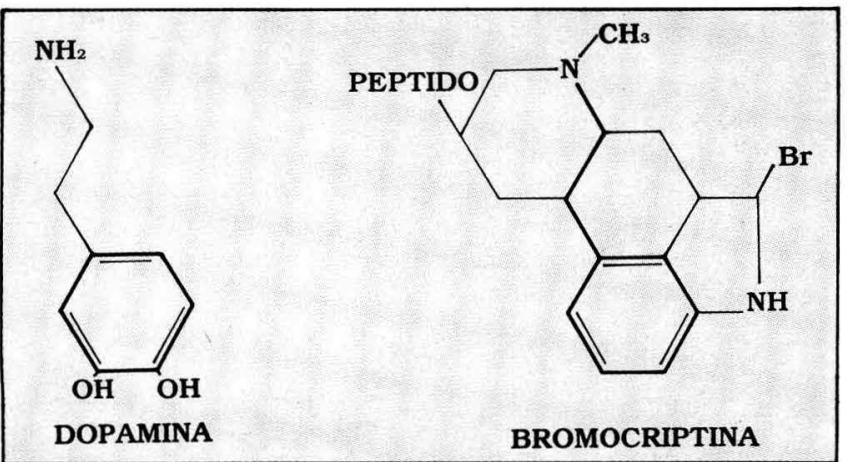

El medicamento se absorbe en 40 a $90 \%$, tiene una vida media de 4 a 8 horas y suprime los niveles de PRL por 20 a 30 horas. Se metaboliza en el hígado y se excreta por heces $(90 \%)$ y orina $(10 \%)$. Actúa estimulando receptores de DA de los lactotropos por un mecanismo que no involucra al AMPc; interfiere con el influjo de calcio, disminuye las síntesis de ADN y RNA m y la actividad mitótica de los lactotropos y aumenta los niveles de DA en el sistema porta (17, 29, 32). Estudios experimentales muestran que la bromocriptina inhibe el crecimiento de los tumores hipofisiarios (33).
Con el tratamiento médico, desaparece la galactorrea en 2 a 4 semanas en un $70 \%$ y se reanudan las menstruaciones en 3 a 10 semanas en un $80 \%$ de pacientes. Se logra ovulación en un $80 \%$ y mejoría de la insuficiencia luteal en un $90 \%$ aproximadamente. (16, 17, 32). En una paciente se logró la reaparición de la menstruación con bromocriptina treinta años después de establecida la amenorrea (34).

La bromocriptina disminuye el tamaño de los prolactinomas en aproximadamente un 40 a 80 de pacientes $y$ es efectiva en el manejo de macroprolactinomas que comprometen estructuras neurológicas y vasculares. $(35,36,37,38,39,40,41,42)$. En algunos casos la disminución del tamaño del tumor y la desaparición de las alteraciones neurológicas es muy rápida $(37,43)$. Así, la bromocriptina es el tratamiento de elección para micro y macroadenomas. Cuando se planea manejo quirúrgico, el tratamiento previo con bromocriptina puede reducir el tamaño del tumor y facilitar el procedimiento $y$, cuando persisten alteraciones postoperatorias, es efectiva como tratamiento complementario (37).

La duración del tratamiento con bromocriptina no se ha determinado; ocurre recurrencia de la hiperprolactinemia y cambios en el volumen tumoral al suspender el medicamento, por lo cual, debe tenerse precaución en pacientes con lesiones grandes; $(43,44)$ algunas pacientes requerirán terapia indefinida. Sin embargo, se han descrito pacientes con reducciones estables en el tamaño del adenoma y el nivel de PRL después de suspender estables la bromocriptina (41).

El tratamiento se inicia con $1.25 \mathrm{mg} V \mathrm{O}$ administrados por la noche y se aumenta progresivamente hasta una dosis promedio de 5 a $7.5 \mathrm{mg}$ (dividido en dosis iguales administradas con las comidas). La dosis de sostén depende de la respuesta clínica y de los niveles de prolactina. La mayoría de los efectos colaterales son transitorios e incluyen náuseas, vómito, hipotensión postural y cefalea (17)

Otros medicamentos que disminuyen la PRL son el mesilato de lergotrilo y la metergolina; la experiencia con ellos es limitada.

c. Tratamiento quirúrgico. El uso del microscopio ha permitido la microdisección de los tumores y de los lóbulos hipofisiarios. Las vías de acceso más utilizadas para la cirugía transesfenoidal son la transeptal sublabial y la transeptal intranasal (45). El tratamiento quirúrgico en los microprolactinomas corrige la hiperprolactinemia, previene la recurrencia y preserva la hipófisis en un 60 a $90 \%$ de pacientes; el éxito de la cirugía disminuye al aumentar el volumen tumoral $(46,47,48)$. Con tratamiento quirúrgico se observó 
recaída en 4 de 5 pacientes con macroadenomas y 12 de 24 pacientes con microadenomas, que habían normalizado los niveles de PRL en el postoperatorio (49). Pueden persistir alteraciones de la regulación hipotalámica de la secreción de PRL aun meses después de la cirugía es la experiencia del centro hospitalario de remisión.

d. Radioterapia. Las técnicas de tratamiento empleadas son: radioterapia convencional, radioterapia con haz de protones, partículas alfa e implantación de itrio -90 u oro radioactivo. La radioterapia convencional se indica como coadyuvante del tratamiento quirúrgico con resección incompleta de un tumor supraselar (51). Las complicaciones de la radioterapia convencional incluyen panhipopituitarismo y radiación de áreas corticales cerebrales. El tratamiento médico ha desplazado también la radioterapia en estos casos.

\section{F. Hiperprolactinemia y embarazo.}

$95 \%$ de los embarazos en pacientes con microadenomas no tratados y $64 \%$ en pacientes con macroadenomas no tratados cursaron asintomáticos; en pacientes con tumores tratados, más del $90 \%$ cursaron asintomáticas y sólo 1 a $2 \%$ requirieron tratamiento (52). El riesgo de aumento de volumen, clínicamente importante, de un mi- croadenoma durante el embarazo es bajo, varía desde 1.6 a $5.5 \%$ y el de un macroadenoma varía desde 15.5 a $35.7 \%$ (52). La hemorragia en un adenoma es un evento raro (52). No hay influencia del tumor ni del tratamiento sobre la tasa de abortos o malformaciones congénitas; la incidencia de malformaciones en 1.000 niñas de madre que recibieron bromocriptina en el embarazo fue similar a la de madre control (53). La mayoría de las pacientes se pueden manejar expectantemente y con controles se campimetría; (27) la aparición de los síntomas ocurre en forma ordenada (cefalea, alteraciones de campo visual, alteraciones neurológicas) y, cuando se requiere, la bromocriptina es el tratamiento de elección en el embarazo (51). También se han practicado con éxito tratamientos quirúrgicos durante el embarazo.

La vía del parto depende solamente de las condiciones obstétricas; si ocurren complicaciones por el tumor y el feto está maduro está indicada la inducción del parto. En el postparto, la paciente puede lactar sin complicaciones y el tratamiento con bromocriptina puede diferirse por 4 a 6 meses (17). No hay diferencia en el riesgo de recurrencia de la hiperprolactinemia después de cirugía transesfenoidal, entre las pacientes que quedaron embarazadas y aquellas que no quedaron embarazadas (48).

\section{BIBLIOGRAFIA}

1. SHOME, B.; PARLOW, A. Human pituitary prolactin: the entire aminoacid sequence. J Clin Endocrinol Metab 45: $1112,1977$.

2. KEIFER, K.A.; MALARKEY, W.B. Size heterogeneity of human prolactin in CSF and serum: experimental conditions that alter gel filtration patterns. J Clin Endocrinol Metab 46: 119, 1978.

3. YEN, S.S.C. Prolactin in human reproduction in YEN SSC, JAFFE RB, Reproductive Endocrinology. Physiology, Pathophysiology and Clinical management. 2 Ed. WB. Saunders Ca, Philadelphia 1986, Pp 237.

4. FARKOUH, N.H.; PACKER, M.G.; FRANTZ, A.G. Large Molecular PRL with reduced receptor activity in human serum: High proportion in basal state and reduced after TRH. J Clin Endocrinol Metab 48: 1026, 1979.

5. ARCHER, D.F. Fisiología de la prolactina. Clin Obstet Ginecol 2: 321, 1980.

6. TYSON, J.E.; HWANG, P.; GUYDA, H. et al. Studies of prolactin secretion in human pregnancy, Am J Obstet Gynecol 113: 14, 1972.

7. BEN-JONATHAN, N. Dopamine: a prolactin-inhibiting homone, Endocrin Revier 6: 564, 1985.

8. HO YUEN, B. Prolactin in human milk: influence of nursing and the duration of postpartum lactation. Am J Obstet Gynecol 15: 583, 1988.

9. JOSIMOVICH, J.B.; ARCHER, D.F. The rol of lactogenic homones in the woman and the fetus. Am J Obstet Gynecol 129: 777, 1977.
10. MASLAR, I.A.; RIDDICK, D.H. Prolactin Production by human endometrium during the normal menstrual cicle. Am J Obstet Gynecol 135: 751, 1979.

11. HAMMOND, C.B. Prolactin syndromes. Clinical advances in reproductive endocrinology and infertility. The American Fertility Society and Serono Symposia. USA 50, 1983.

12. KORDON, C.; BLAKE, C.A.; TERKEL, J. et al. Participation of serotonincontaining neurons in the suckling-induced rise in plasma prolactin leves in lactating rats. Neuroendocrinology 13: 213, 1974.

13. WEST, B.; DANNIES, P.S. Effects of estradiol on prolactin production and dihydroergocriptine-induced inhibition and prolactin production by primary cultures of rat pituitary cells. Endocrinology 106: 1108, 1980.

14. PRIOR, J.C.; COX, T.A.; FAIRHOLM, D. et al. Testosterone related exacerbation of a prolactin producing macroadenoma: possible role for estrogen. J Clin Endocrinol Metab 64: 391, 1987.

15. MALARKEY, W.B. Prolactin and the diagnosis of pituitary tumors. Ann Rev Med 30: 249, 1979.

16. DEL POZO, E. Prolactin. Curr Conc Obstet Gynecol 93, 1979.

17. BARBIERI, R.L.; RYAN, K.J. Bromocriptine: endocrine pharmacology and therapeutic applications. Fertil Steril 39: 727, 1983. 
18. McCARTY, K.S.; DOBSON II CE. Patologia Hipofisiaria asociada con anormalidades de la secreción de PRL. Clin Obstet Gynecol 2: 365, 1980.

19. WIEBE, R.H. Valoración endocrina de hiperprolactinemia. Clin Obstet Gynecol 2: 347, 1980.

20. MULCHAHEY, JJ.; JAFFE, R.B. Detection of a potential progenitor cell in the human fetal pituitary that secretes both growth hormone and prolactin. J Clin Endocrinol Metab 66: 24, 1987.

21. LUNDBERG, P.O.; OSTERDAM, P.O.; WIDEL, L. Serum prolactin in patients with hypothalamus and pituitary disorders. J Neurosurg 55: 194, 1981.

22. THOMAS, R.; REID, L. Thyroid disease and reproductive dysfunction: a review. Obstet Gynecol 70: 789, 1987.

23. GRUBB, M.R.; CHAKERES, D.; MALARKEY, W.B. Patients with primary hypothytoidism presenting as prolactinomas. Am J Med 83: 765, 1987.

24. ROTH, J.; GRUNFELD, C. Mechanism of action of peptide hormones and catecholamines. In Wilson JD, Foster DW (Eds): Williams Textbook of Endocrinology. Philadelphia WB Saunders Pp 76, 1985.

25. FRADKIN, J.E.; EASTMAN, R.C.; LESNIAK, M.A. et al. Specificity Spillover at the hormone receptor-Exploring its role in human disease. New Engl J Med 320: 640, 1989.

26. QUIGLEY, M.M.; HANEY, A.F. Valoración de hiperprolactinemia, Perfiles Clinicos. Clin Obstet Gynecol 2: 333, 1980.

27. ORDAZ, J. Prolactinomas: un problema diagnóstico y terapéutica. Sandorama 1: 23, 1985

28. SHEARMAN, R.P. Secondary amenorrhoea. In SHEARMAN RP Clinical Reproductive Endocrinology. Churchill Livingstone. Endinburgh Pp 493, 1985.

29. GUITELMAN, A. Use of bromocriptine as a diagnostic and therapeutic tool in hyperprolactinemic states. Recent advances in infertility research: developments in reproductive endocrinology. Alan $\mathrm{R}$ Liss Inc. New York Pp 255, 1982.

30. HARDY, M,; O’CONNELL, J.; GILBERTSON, N. et al. Precocious puberty associated with hyperprolactinemia in a male patient. J Pediatrics 113: 508, 1988.

31. HIGUCHI, K.; NAWATA, H.; MAKI, T. et al. Prolactin has a direct effect on adrenal androgen secretion. J Clin Endocrinol Metab 59: 714, 1984.

32. VAUGHN, T.C.; HAMMOND, C.B. Tumores hipofisiarios productores de prolactina: terapeutica médica. Clin Obstet Gynecol 2: 403, 1980.

33. MacLEDD, R.M.; LEHMEYER, J.E. Supression of pituitary tumor growth and function by ergot alkaloids. Cancer Res 33: 849, 1973.

34. GOLDMAN, M.; STEINBERGER, GANTI, S. Hyperprolactinemia with prolonged amenorrhea reversed with bromocriptine in a menopausal woman Am J Obstet Gynecol 158: 117, 1988.

35. SPARK, R.F.; BAKER, R.; BIENFANG, D.C. et al. Bromocriptine reduces pituitary tumor size and hypersecretion: requiem for pituitary surgery. JAMA 247: 311, 1982.

36. GEORGE, S.R.; BURROW, G.N.; ZINMAN, B. et al. Regression of pituitary tumors a possible effect of broergocryptine. Am J Med 66: 697, 1979.
37. MOLITCH, M.E.; ELTON, R.L.; BLACKWELL, R.E. et al. Bromocriptine as primary therapy for prolacting macroadenomas: results a prospective multicenter study. J Clin Endocrinol Metab 60: 698, 1985.

38. VELENTZAS, C.; CARRAS, D.; VASSILOUTHIS, J. Regression of pituitary prolactinoma with bromocriptine asministration JAMA 245: 1149, 1981.

39. JOHNSTON, D.G.; PRESCOTT, R.W.G.; KENDALL, T.P. et al. Hyperprolactinemia. Long-term effects of bromocriptine. Am J Med 2: 700, 1983.

40. WASS, J.A.H.; WILLIAMS, J.; CHARLESWORTH, M. et al. Bromocriptine management of large pituitary tumors. Br Med J 284: 1908, 1982.

41. MORIONDO, P.; TRVAGLINI, P.; NISSIM, M. et al. Bromocriptine treatment of microprolactinomas: evidence of stable prolactin decrease after drug withdrawal. J Clin Endocrinol Metab 60: 764, 1985.

42. McGREOR A.M.; SCANLOM, M.F.; HALL, R. et al. Bromocriptine on pituitary tumor size. Br Med J 2: 700 , 1979.

43. THORNER, M.D.; MARTIN, W.H.; ROGOL, A.D. et al. Rapid regression of pituitary prolactinomas during bromocriptine treatment. J Clin Endocrin Metab 51: 436, 1980.

44. THORNER, M.D.; PERRYMAN, R.; ROGOL, A.D. et al. Rapid Changes of prolactinomas volumen after withdrawal and reinstitution of bromocriptine Journal Clinic Endocrinologic and Metabolism 53: 480, 1981.

45. KENAN, P.D. Accesos Guirúrgicos para tumores hipofisiarios Clin Obstet Ginecol 2: 413, 1980.

46. DOMINGUE, J.N.; RICHMOND, I.L.; WILSON, C.B. Results of surgery in 114 patients with prolactinsecreting pituitary adenomas. Am J Obstet Gynecol 137: $102,1980$.

47. POST, K.D.; DILLER, B.J. ADELMAN, L.S. et al. Selective transphenoidal adenomectomy in women with galactorrea amenorrhea JAMA 242: 158, 1979.

48. SCHLENCHTE, J.; VANGILDER, J.; SHERMAN, B. Predictors of the outcome of transphenoidal surgery for prolactin- secreting prolactin-secreting pituitary adenoma. J Clin endocrinol Metab 52: 785, 1981.

49. SERRI, O.; RASIO, E.; BEAUREGARD, $H$. et al. Recurrence of hyperprolactinemia after selective transphenoidal adenomectomy in women with prolactinoma. N Engl J Med 209: 280, 1983.

50. TUCKER, G.; LANKFORD, H.V.; GARDNER, D.F. et al. Persistent defect in regulation of prolactin secretion after successful pituitary-tumor renmoval in women with galactorrhea-amenorrhea syndrome. J Clin Endocrinol Metab 51: 968, 1980.

51. NOELL, K.T. Tumores hipofisiarios productores de prolactina y de otras hormonas: Terapéutica por radiación. Clin Obstet Gynecol 2: 443, 1980.

52. MARSHALL, J.R. Embarazo en pacientes con tumores hipofisiarios productores de prolactina. Clin Obstet Gynecol 2: 457, 1980.

53. GRIFFITH, R.W.; TURKALY, I.; BRAUNN, P. Outocome of pregnancy in mother given bromocriptine. $\mathrm{Br} \mathrm{J}$ Clin Pharmacol 5: 227, 1978. 